\title{
Tirar o aborto da sombra. A condição fetal: uma sociologia do engendramento e do aborto
}

\author{
La condition foetale: une \\ sociologie de l'engendrement e \\ de l'avortement.
}

BOLTANSKI, LUC.

Pa ris: Gallimard, 2004. 420 p.

O sociólogo Luc Boltanski estuda as dimensões nomativas da atividade humana, os sensos de justiça e de moral nas sociedades complexas, tendo publicado várias obras a respeito (L'amour et la justice comme compétences; De la justification; La soufrance à distance; Le nouvel esprit du capitalisme). A pesquisa sobre engendramento e aborto permite confrontar um objeto no qual a contradição é dimensão integrante e coloca disputas sobre a questão do que é justo. Boltanski constrói um modelo teórico a o contra por dados empíricos e outras disciplinas além da sociologia, como a antropologia, a filosofia, a psicanálise, com a ná lise das implic ações lega is, em abordagem original que responde à reflexão feminista.

O livro La condition foetale: une sociologie de l'engendremente et de l'avortement consta de sete capítulos, além da introdução e da conclusão. O autor pretende tratar o objeto "aborto" com dista ncia mento, em aborda gem no domínio da sociologia moral. Seu primeiro objetivo teórico é considerar o problema da separação entre o que se sabe de modo oficial e de modo oficioso, um conhecimento tácito a respeito de que se abrem os olhos e se fecham os olhos em momentos diferentes. O segundo objetivo teórico é fazer a convergência de três aborda gens distinta s: 1) esboçar uma gramátic a do engendramento revelada pelo aborto, especificando os constrangimentos sobre a confecção de novos seres humanos, nas dimensões contra ditórias dos dispositivos socia is 
que enquadram a geração; 2) a nalisar a experiência das pessoas; 3 ) uma terceira abordagem de caráter histórico sobre os dois constrang imentos na dimensão a ntropológ ic a. A pesquisa na França foi trabalho em equipe: observação em serviços de ginecologia recolhendo dados no atendimento de cem usuá rias. Houve entrevista sem profund ida de com mulheres que a borta ra $\mathrm{m}$, e com profissiona is dos serviç os e médicos participantes do movimento de legalização. Levantaram-se a iconografia de imagens da vida fetal e a documentação em diversos domínios das ciências socia is.

o primeiro capítulo aborda as dimensões antropológicas do aborto, uma prática conhecida e difundida em todas as socieda des. O aborto coloca para a sociologia duas questões: a primeira acerca da legitimidade (geralmente é reprovado em princípio e tolerado na prática, pertencendo a o domínio do ofic ioso); a segunda relaciona sua generalidade e visibilidade (embora conhecido e freqüente, o aborto é raramente representado). Essas duas propriedades (a ambigüidade quanto à normatividade e a recusa da representação) estão relacionadas a tensões acerca do engendramento: para sua inserção em sociedade os seres humanos são objeto de um processo de singularização. 0 estabelecimento de relações de parentesco e a singula rização dos indivíduos são acompanhados do processo de desacoplamento do engendramento e da sexualidade, esta orienta da para o prazerou para a reprodução. 0 modelo de engendramento tem dois aspectos: a possibilidade de se desfazer de seres humanos resultantes da relação sexual é condição da criação de novos seres humanos inscritos na carne que são retomados simbolicamente e adotados para se tornar singulares; a destruiçã o dos fetos engendradosé ato problemático, transgressivo e difícil de legitimar.

O segundo capítulo esboça o modelo (gramática)de engendramento do qual emanam os dois constrang imentos principa is. A a borda gem é construtivista, perguntando os pontos mínimos exigidos para fazer seres humanos: 1) 0 pertencimento à espécie humana; 2) seres a rranjados em classes equivalentes de outros seres pertencentes à espécie humana; 3 ) seres singularizá veis. Tomando por referência a antropologia social, Boltanski afirma que a diferença que fazos huma nos está em considerálos humanos pela came (nascido de mulher a partir de relações sexuais) e humanos pela palavra (reconhecidos em sua humanidade por rituais que os inserem nos coletivos). A singularização ou confirmação pela palavra permite a existência de várias classes de indivíduos sem confundi-los. Exemplos de seres humanos pela came e não pela palavra estão nas situações de infantic ídio e de escravidão. 0 autor define dois constrangimentos do engendramento: 1) "é necessário que seja marcada a diferença entre seres engendrados pela came e seres engendrados pela palavra" (p. 69); 2) "os seres pela came não podem ser distinguidos dos seres pela palavra, de sorte que não se deve fazer os primeiros sofrerem um tra tamento que não se quereria fazerossegundos sofrerem" (p. 80). 0 primeiro constrangimento se relaciona ao processo de confirmação da humanidade pela mãe do servindo na gravidez, o que desencadeia o processo de singularização. Seres nã o confima d os seria m sub stituíveis porque não singula rizados como nas situações do infanticídio e do aborto. Esse raciocínio estabelece uma concepção dualista de humanidade que contraria as teorias da justiça representadas no segundo constrangimento: a não-disc riminação entre os seres. Há contra dição entre os dois constrangimentos. O autor problematiza a noção de humanidade comum, estabelecida pelo segundo constrangimento. Enquanto o primeiro constrangimento adota 0 ponto de vista da mãe, o segundo a dota o ponto de vista do observador extemo que coloca o problema da similitude dos seres e da desigualdade de seu tra tamento.

O capítulo 3 trata dosa ranjos: os dispositivos que permitem suavizar a tensão entre os dois constrangimentos a o organizar a relação entre sexualidade e engendramento. Nos a rranjos, 0 poder da mãe é subordinado a uma autoridade superior que assegura a confirmação pela palavra do ser engendrado na carne. Aí se contrapõem a ordem do oficial e a ordem do oficioso, tendo hipocrisia e má-fé por proprieda des estrutura is. Há qua tro a rra njos: com - Deus Criador que pré-confirma 0 engendramento, estando a sexua lidade a serviço deste; 0 a rranjo doméstic o com o parentesc o que pré-confirma apenas crianças a nascer em legitimidade e dispõe homens e mulheres em posições diferentese a ssimétric as; com o Esta donação, que visa a gerar população de boa qualidade, fazendo da reprodução objeto de intervenção pública e eliminando entes inúteis para a sociedade. O Estado mostra autoridade sobre o engendramento, descriminando ou não 0 aborto segundo polític as populaciona is. 
O último a rranjo é o tema do quarto capítulo: o projeto parental, esboçado durante mudanç as soc ia is rec entes no contexto social da lega liza ção do a borto em diversos países. 0 autor formula esse a ranjo com base nas justific ativas para o aborto dadaspelasinformantes. No projeto parental, ta mbém se dissociam engendramento e sexualidade, com ênfase na última, o que depende da eficácia dos métodos de contracepção. 0 aborto lega liza do seria palia tivo para as falhas da contracepção. O projeto parental c onstitui a instância supra-individual de pré-confirmação da criança a nascer: o engajamento dos genitores é condição para singularizá-la e insc revê-la plenamente no mundo. A incidência do aborto dever-se-ia menosa falhas da contracepção do que a falhas no engendramento, quando este escapa ao quadro do projeto. Constatam-se três situa ções básicas: a gravidezacidental na ausência de projeto (sexo casual); o a borto como instrumento de um projeto diferido (projeto de gravidez no futuro); o projeto posto em xeque (divergência das intenções do casal diante da gravidez). Muitas vezes o companheiro recusa a gravidez, porém, quando a mulher decide pelo aborto, ela se justific a não a penas por dificulda des ma teria is ou por outros projetos, mas também pela insuficiência do genitor. Foram raras as respostas sobre o aborto como escolha autônoma e direito pessoal, ou de a mulher assumir a gravidez fora do projeto parental. 0 discurso libertário dos anos 60 decai no contexto da legalização e de surgimento do a rranjo parental, em que o aborto permanece marginal e tem papel oficioso.

O capítulo 5 traza construção de categorias feta is deduzidas do disc urso dos informantes, de peritose dos textos juríd ic os. No a rra njo parental, há eng end ra mento com ca ra c terístic a sopostas: valoriza-se o feto autêntic o integrado a o projeto parental, a companha-se seu desenvolvimento e este é reconhecido como pessoa e destina do ao futuro, enqua nto o feto tumoral não integra do a o projeto volta ao nada. O feto essencialista (do a rranjo com Deus) se pretende fora da história, designa do de natura lista, pois oriund o da ordem natural fundada no Criador. A autoridade da Ciência legitima sua singularidade a partir da dotação genética e das técnicas de imagem. 0 feto bárbaro (arranjo com parentesco) brota como vida animal fora do projeto, sem singularidade, ou resulta da dominação patriarcal. O feto tota litário (a rra njo com o Estado) relaciona-se às políticas de população e à eugenia, com téc nic as de diagnóstic o pré-natal que permitem evitar nascimentos mediante 0 a borto tera pêutic 0 . Os meios tec nológ ic os como a reprodução assistida e os dispositivos juŕd ic os criam novas categorias, ao estabelecer direitos do feto dentro do útero, ou cirurgias fetais. A categoria de tecnofeto surge do desenvolvimento tecnológic o como embriões congelados da fertiliza ção in vitro. 0 deba te sobre o estatuto legal do embrião fora do corpo relaciona-se às fronteiras da humanidade. Desestabiliza-se a distinção entre o feto autêntic o e o tumoral com o advento do tecnofeto, e da visualização dos fetos no útero por tecnologias de imagem e no uso de fotografias por grupos anti-aborto. Os conflitos envolvendo o feto e as tecnologias que o to ma ram ac essível a os sentid os permitira $m$ sua entrada na sociedade. Desconstrucionistas contestam a crença no feto em si dotado de atributos permanentes e o mostram como ser histórico e social. Boltanski propõe a abordagem construcionista a partir de categorias seguindo os delineamentos da língua e as construções metafísicas da cultura. O feto tumoral corresponderia à categoria a ristotélica de acidente e à contingência; o feto autêntic 0 , à virtualida de e a o projeto; e o tec nofeto à potência da humanidade questionada.

0 enfoque sobre a justificação do aborto encontra-se no capítulo 6 . Com base na filosofia moral anglo-saxônica, examina-se: o estabelecimento de leis de despenalização, a tentativa de fazerdo a borto lega liza do um direito e a busca de sua legitimação moral. No momento de despenalização, a colocação do aborto no espaço público transgrediu a separação entre as dimensões ofic ia is e as ofic iosas dos a rra njos do engendramento que são questionados. Mudou o regime político do feminino. Apaga-se a cidade doméstica (cf. De la justification), a ordem política a poiada nas formas de subord ina ção associa das ao modelo do parentesco, com cadeias de dependências pessoais. A crítica ao mundo doméstico se estende a os poderes instituc iona is, e desemboca na apologia da autonomia e da realização de si. As leis de despenalização do aborto na França e nos Estados Unidos tratam a mbiguamente o feto. Definir se o feto é ou não pessoa constitui o eixo da discussão sobre a possibilidade de opor os direitos da mulher e do feto. No debate filosófic 0 , constrói-se o feto a partir de sua substância ou a partir de sua relação com a mãe. Na concepção do feto como substância, o autor limita-se a descrever posições que atribuem ou negam ao feto uma substância própria. Há posições de ca ráter gradualista debatendo a etapa a partir da qual o embrião se toma pessoa, ${ }^{1}$ ignoradas no livro. Boltanski 
descreve abordagens utilitaristas que propõem a distinção entre pessoa e ser humano, ou que calculam o valor moral dos entes. Outros argumentos enfocam a relação do feto com a mãe na comparação do feto a um intruso, e no reconhecimento do feto como condição do direito à vida. As posições desc onstruc ionistas das c iênc ia s soc ia is questiona mo "na tura lismo", que trata como oriundas da natureza crenças e práticas pertinentes a a ranjos socia is va riá veis. Para Boltanski, o principal problema nesses esquemas de argumentação é a desqua lific ação da noção de humanidade comum. Os filósofos mora is esqueceram a experiência de sofrimento das mulheres no aborto, o que remete à abordagem jurídica em termos do mal menor.

o capítulo 7 aborda a experiência do a borto. Enqua nto as filo so fia s feminista s enfatizam o sofrimento da mulhere contestam a concepção liberal que contra põe os direitos da mãe e os do feto, Boltanski conclui que as categorias que organizam o discurso político ou moral sobre o a borto são pouco úteis para compreendero que as entrevista das dizem. Elas não se separam como sujeito autônomo do outro ser distinto em seu corpo. O autor desenvolve um modelo de inspiração freudiana. As informantes ma nifestam tensão entre diferentes vontades: vontade da carne (ligada à instância do Si, à experiência da came grávida, inscrita no presente), vontade de domínio (ligada à instância do Eu, ao projeto, dirigida ao futuro) e vontade de legitimação (liga da à instância da justific ação, à explicação, retrospectiva). A gravidez ocorre entre plenitude e inquietude, e há a mbiva lência no conflito entre vontade de domínio e vontade da came. No projeto, conferem-se a o feto esta tutos diferentes: o autêntico que vai nascer ou o tumoral, sem futuro. A vontade de legitimação explica circunstâncias e dá sentido à ação em três registros observa dos: segundo a vontade (lógica do projeto), a necessidade diante de circunstância s extemas e correspondênc ias entre fatos. A came não faz diferença entre fetos, por isso é difícil realizar a vonta de de domínio. Fazer filhos com seres insc ritos na came, ou se desfazer deles recusando o reconhecimento pela palavra, jamais esteve completamente sob o império do "Eu" e da vontade de domínio.

Que razões para fazer o aborto desaparecer? Fecham-se os olhos ao aborto por ser uma ação orientada pela lógica do menor mal. Os contrários querem proibição e repenalização do aborto, que retornaria à clandestinidade. Os favoráveis o encobrem ao propor sua "desdramatização" como a to banal, posição pouco sensível ao sofrimento das mulheres, tachado de feminilidade dependente da maternidade. Na ausência da dimensão trágica de se desfazer do engendrado, há a questão de definir as fronteiras da humanidade. $\mathrm{O}$ aborto é objeto de conflito por expor tensões inerentes ao engendramento, reveladas como contra dição. O problema da condição humana subjaz às perguntas sobre engendramento e condição fetal.

A análise de Boltanski desafia estudos de gênero e movimentos feministas que, na defesa de bandeiraspolíticas, afastam-se da percepção das mulheres não milita ntes. 0 aborto se mantém na sombra mesmo nos países onde é legalizado, o que remete a os sistemas de engendra mento e à condição de pessoa, um contexto do qual fazem parte as técnicas de imagem fetal, a produção dos tecnofetos, o a parato jurídico e a experiência das mulheres.

\section{Nota}

${ }^{1}$ Cf. Tânia SALEM, 1997.

\section{Referência bibliográfica}

SALEM, Ta nia. "As novas tec nolog ias reprodutivas: o esta tuto do embrião e a noção de pessoa". Mana, v. 3, n. 1, p. 75-94, 1997.

Naara Luna Universida de Federal do Rio de J a neiro 